\title{
Correction to: Integer codes correcting burst asymmetric errors within a byte and double asymmetric errors
}

\author{
Aleksandar Radonjic ${ }^{1} \cdot$ Vladimir Vujicic $^{1}$ \\ Published online: 23 August 2019 \\ (C) Springer Science+Business Media, LLC, part of Springer Nature 2019
}

\section{Correction to: Cryptography and Communications https://doi.org/10.1007/s12095-019-00388-0}

The original version of this article unfortunately contained a mistake in the main title. Instead of "Integer codes correcting burst asymmetric within a byte and double asymmetric errors" the title should read "Integer codes correcting burst asymmetric errors within a byte and double asymmetric errors".

Publisher's note Springer Nature remains neutral with regard to jurisdictional claims in published maps and institutional affiliations.

The online version of the original article can be found at https://doi.org/10.1007/s12095-019-00388-0

Aleksandar Radonjic

sasa_radonjic@yahoo.com

Vladimir Vujicic

vujicicv@yahoo.com

1 Institute of Technical Sciences of the Serbian Academy of Sciences and Arts, Belgrade, Serbia 